\title{
O HOMEM E A CRÍTICA EM AS PALAVRAS E AS COISAS: KANT, NIETZSCHE, FOUCAULT E ALÉM
}

\section{MAN AND CRITICISM IN THE ORDER OF THINGS: KANT, NIETZSCHE, FOUCAULT AND BEYOND}

\author{
Marco Antônio Sousa Alves*
}

\section{RESUMO}

$\mathrm{O}$ artigo pretende colocar na luz dois temas centrais em As palavras e as coisas: a questão do nascimento e da morte do homem e a reflexão sobre o que caracteriza uma filosofia crítica. $\mathrm{E}$ ao olhar para esses dois grandes eixos, duas referências incessantes no pensamento de Foucault terão maior destaque: Kant e Nietzsche. O artigo pretende acompanhar a presença desses filósofos em As palavras e as coisas, destacando a importância deles no desenho do projeto arqueológico. Além disso, o artigo defenderá que As palavras e as coisas pode ser lida como uma autêntica experiência de pensamento que exemplifica a postura crítica da "ontologia do presente", encarnando o ethos filosófico que no final de sua vida Foucault chamará de "atitude de modernidade".

PALAVRAS-CHAVE: Homem. Crítica. Foucault. Kant. Nietzsche.

\section{ABSTRACT}

This article intends to put light on two central issues in The Order of Things: the question of birth and death of man and the reflection on what characterizes a critical philosophy. Looking at these main lines, two incessant references in Foucault's thought will gain more prominence: Kant and Nietzsche. This article aims to follow the presence of such philosophers in The Order of Things, highlighting their importance in the design of the archaeological project. Furthermore, the article advocate that The Order of Things could be read as an authentic experience of thinking that illustrates the critical stance of the "ontology of the present", embodying the philosophical ethos that Foucault will call, at the end of his life, "attitude of modernity".

KEYWORDS: Man. Critique. Foucault. Kant. Nietzsche.

\footnotetext{
* Doutor em Filosofia - UFMG. Pesquisador de Pós-Doutorado (PNPD/CAPES) - Filosofia - UFMG. E-mail: marcofilosofia@yahoo.com.br
} 


\section{INTRODUÇÃO}

Cinquenta anos atrás, em 1966, vinha a público na França As palavras e as coisas (Les mots et les choses), causando grande repercussão e intensas polêmicas. O sucesso da obra foi imediato. A revista Le Nouvel Observateur estampou em sua edição de 10 de agosto de 1966 que Foucault "vendia como banana" ou, na expressão francesa, como pãezinhos (Foucault comme des petits pains). Este foi certamente o livro que projetou Foucault e conferiu a ele a estatura de grande filósofo francês de seu tempo. Apesar disso, seu percurso intelectual fez com que sua imagem de arqueólogo do saber fosse aos poucos se desvanecendo diante de um novo Foucault cada vez mais associado ao projeto de uma genealogia do poder. Suas inflexões metodológicas, os novos temas introduzidos e os best-sellers publicados nos anos 1970, quais sejam, Vigiar e punir (1975) e o primeiro volume da História da sexualidade (1976), que ainda hoje figuram na lista dos livros mais citados no mundo na área das Humanidades, fizeram com que As palavras e as coisas fosse cada vez mais vista como uma obra datada, símbolo de uma época (o estruturalismo francês dos anos 1960), enfim, um grande livro, mas que teria sido superado, em grande parte por seu próprio autor.

Contribuiu ainda mais para esse fenômeno o fato de As palavras e as coisas ser considerado um livro "difícil", carregado de "reflexões densas" e repleto de referências à tradição filosófica (Descartes, Kant, Nietzsche, Husserl, Heidegger, etc.). O próprio Foucault dos anos 1970 condenará seu estilo dessa época, que estaria perto demais da "grande filosofia" e das "grandes ideias", longe do estudo mais centrado nas práticas e nas relações efetivas de poder. Soma-se ainda a esse rebuscamento filosófico o diálogo minucioso que o livro estabelece com diversas áreas das ciências, passando pela economia, biologia, filologia, história, psicanálise, etnologia, entre outras. Tudo isso parece ter provocado certo receio em relação ao livro, especialmente entre os novos leitores que Foucault conquistou nos mais diversos campos do saber (como os juristas, os psiquiatras, os psicólogos, os historiadores, os pedagogos, os sociólogos, os cientistas políticos, os médicos, etc.), muitos deles pouco familiarizados com a "grande filosofia". E mesmo os "filósofos de profissão" tenderam a afastar-se de As palavras e as coisas nos últimos anos, em razão do interesse despertado pelo "novo Foucault" que cada vez mais aparecia com a publicação póstuma de um vasto material, como os Ditos e escritos nos anos 1990 e, mais recentemente, os cursos dados no Collège de France, cuja publicação foi encerrada apenas ano passado na França. 
Diante deste cenário, creio que esse ano de comemoração do cinquentenário de publicação de As palavras e as coisas constitui uma ótima oportunidade para revisitarmos essa obra monumental com outros olhos. E essa volta, como em geral acontece com os livros “clássicos", tende a reservar algumas gratas surpresas. Como dizia Ítalo Calvino, clássicos são aqueles livros que a cada releitura oferecem uma sensação de descoberta, eles nunca esgotam o que têm a dizer, e quanto mais se acredita conhecê-los, mais originais, inesperados e inovadores o consideramos quando voltamos a lê-los (CALVINO, 1993).

Este artigo pretende compartilhar um pouco dessa experiência de volta a um livro clássico. Dois temas centrais em As palavras e as coisas serão colocados na luz: a questão do homem e a reflexão sobre o que caracteriza uma filosofia crítica. E ao olhar para esses dois grandes eixos, sobre os quais podemos dizer que todo o livro se articula, duas referências incessantes no pensamento de Foucault se sobressaíram: Immanuel Kant e Friedrich Nietzsche. Proponho então começar esta análise pela questão do homem e, em seguida, investigar o problema da crítica. Nos dois casos, pretendo ressaltar a presença (explícita ou implícita) de Kant e Nietzsche, além de apontar para o fato de que já vemos em As palavras e as coisas uma autêntica experiência de pensamento que exemplifica a postura ou o ethos filosófico que no final de sua vida Foucault chamará de "atitude de modernidade".

\section{O NASCIMENTO E A MORTE DO HOMEM: DE KANT A NIETZSCHE}

A obra As palavras e as coisas é encerrada em grande estilo, com a afirmação de que "o homem é uma invenção cuja recente data a arqueologia de nosso pensamento mostra facilmente. E talvez o fim próximo" (FOUCAULT, 2007, p. 536). E a última frase do livro é uma das mais famosas de Foucault, quase um slogan: "se pode apostar que o homem se desvaneceria, como, na orla do mar, um rosto de areia" (comme à la limite de la mer un visage de sable) (FOUCAULT, 2007, p. 536; FOUCAULT, 1966, p. 398). Essas frases, ditas de forma descontextualizada, podem parecer mais uma vã provocação ou uma sandice filosófica pós-moderna qualquer. Afinal, como pode o homem ser uma invenção recente, prestes a desaparecer novamente? Mas, em que pese o estilo bombástico, quem já se deu ao trabalho de percorrer as mais de 500 páginas (na edição brasileira) ou as quase 400 páginas (na edição francesa) de As palavras e as coisas, sabe que se trata de uma tese rigorosa e pacientemente elaborada.

Sapere aude - Belo Horizonte, v. 7 - n. 12, p. 7-21, Jan./Jun. 2016 - ISSN: 2177-6342 
O foco principal desse livro é bem conhecido: trata-se de estudar o aparecimento contingente da figura (nova) do homem (entre o século XVIII e os dias atuais), figura essa atravessada pelo jogo da vida, da linguagem e do trabalho e que é, ao mesmo tempo, objeto do saber e sujeito que conhece. E ao estudar a emergência do homem, aponta-se também para a possibilidade de seu iminente desaparecimento. Em suma, podemos resumir As palavras $e$ as coisas como uma investigação sobre o nascimento e a morte do homem.

Nessa investigação, dois filósofos aparecem em destaque, como marcos desses dois momentos: Kant e Nietzsche. Kant é visto em As palavras e as coisas como o grande nome da conformação dessa figura do homem (e não Descartes, como muitas vezes se pensa na filosofia). Já Nietzsche se ocupará, pouco mais de um século depois de Kant, de indicar a sua morte. Kant está situado na origem do sonho humanista e antropológico que teria marcado toda a episteme moderna, que conferiu ao sujeito um lugar central e fundador. Já Nietzsche representa aquele que começou a desfazer esse sono antropológico, o polêmico e provocador "assassino" de Deus e do Homem.

O criticismo kantiano é visto por Foucault como uma grande ruptura no campo problemático do saber ocidental, o limiar de uma nova positividade, que torna possível esse aparecimento do homem. Nesse sentido, afirma Foucault que “o fim da metafísica não é senão a face negativa de um acontecimento muito mais complexo que se produziu no pensamento ocidental. Esse acontecimento foi o aparecimento do homem" (FOUCAULT, 2007, p. 437-8). Kant é visto como um pensador que teria revolucionado o campo do saber e aberto o espaço para o posterior desenvolvimento das ciências humanas e da analítica da finitude. Segundo Foucault, em uma das declarações mais polêmicas de As palavras e as coisas: "antes do fim do século XVIII, o homem não existia" (FOUCAULT, 2007, p. 425). Ou seja, sustenta-se que na episteme clássica (em Descartes, por exemplo) simplesmente não encontramos esse homem que vive, fala e trabalha, e que, além disso, tem o direito de conhecer e colocar na luz as leis de seu próprio conhecimento. Kant marca, portanto, o momento de uma "mutação arqueológica", quando o discurso clássico se desvanece e, em seu lugar, "o homem aparece com sua posição ambígua de objeto para um saber e de sujeito que conhece: soberano submisso, espectador olhado" (FOUCAULT, 2007, p. 430).

Deixemos então mais claro que homem é esse que Kant fez nascer. Esse termo "homem" em As palavras e as coisas se refere a uma figura da episteme moderna com duas faces: uma tributária da analítica da finitude (o sujeito moderno da filosofia kantiana e especialmente da fenomenologia) e outra das ciências humanas (o homem que vive, trabalha e 
fala). A analítica da finitude designa, basicamente, o movimento da finitude das empiricidades (da vida, do trabalho e da linguagem) para uma finitude mais fundamental. Por isso há na analítica da finitude uma oscilação entre o positivo e o fundamental, que pode assumir a forma do empírico e do transcendental.

Para Foucault, essa oscilação entre o empírico e o transcendental é um traço característico do homem na episteme moderna. Como deixa claro: "o limiar da nossa modernidade não está situado no momento em que se pretendeu aplicar ao estudo do homem métodos objetivos, mas no dia em que se constituiu um duplo empírico-transcendental a que se chamou homem" (FOUCAULT, 2007, p. 439). Isso porque no ser do homem é preciso que se considere o conhecimento que faz possível todo o conhecimento. Por exemplo, os saberes voltados ao corpo (estudos da percepção, dos esquemas neuromotores, etc.) dão lugar a uma espécie de estética transcendental. ${ }^{1}$

Segundo Foucault: "a antropologia constitui, talvez, a disposição fundamental que comandou e conduziu o pensamento filosófico desde Kant até nós” (FOUCAULT, 2007, p. 473). A antropologia é aqui aproximada a uma espécie de posição humanista, que tende a colocar a figura do homem no centro da filosofia. Foucault situa a revolução copernicana como o movimento filosófico que deu forma ao pensamento antropológico moderno e à analítica da finitude, sendo o homem tomado como um ser finito governado por processos de vida, exigências do trabalho e estruturas da linguagem. Por um lado, um objeto para um saber empírico, por outro, tomado como fundamento das condições de possibilidade do conhecimento. Ou seja, o homem como sujeito transcendental e como objeto determinado.

Podemos dizer que o que incomoda Foucault em Kant não é a crítica transcendental, mas sim a posição central e o poder sintético atribuído ao sujeito. Em outras palavras, a impressão que temos é que Foucault pretende ser, nesse aspecto, uma espécie de "kantiano sem sujeito transcendental" (DEKENS, 2011, p. 164). Em suma, a transformação da crítica kantiana proposta por Foucault em As palavras e as coisas visa matar o homem, o que

\footnotetext{
${ }^{1}$ Embora essa oscilação e confusão entre o empírico e o transcendental tenha marcado a figura do homem na modernidade, Foucault deixa claro que o próprio Kant teria traçado claramente a diferença entre esses dois planos, cabendo à reflexão transcendental indicar como o problema antropológico poderia ser corretamente colocado, sem se cometer um duplo erro especulativo e positivo. Mas, apesar do cuidado de Kant, a episteme moderna teria, aos olhos de Foucault, feito do homem um duplo empírico-transcendental (HUTCHINGS, 1996, p. 108). De certa forma, o antropologismo presente no pensamento pós-kantiano é visto por Foucault como précrítico, e essa confusão se aplicaria ao positivismo, à dialética e à fenomenologia, tanto às análises que atribuem um valor transcendental ao objeto, quanto às que se deslocam para o sujeito constituinte. (CANDIOTTO, 2006, p. 185-186).
}

Sapere aude - Belo Horizonte, v. 7 - n. 12, p. 7-21, Jan./Jun. 2016 - ISSN: 2177-6342 
envolve a morte do sujeito transcendental, mas sem eliminar o gesto crítico de Kant, que deve então ser desenvolvido de outro modo. Foucault pretende se servir da crítica aberta por Kant sem recair no sono antropológico, ou seja, sem qualquer sujeito único e fundador servindo como "apoio transcendental". Em outras palavras, o dispositivo crítico de tipo “transcendental" poderia (e deveria) ser retomado em novos termos.

É nesse ponto que a influência de Nietzsche se faz sentir vivamente em As palavras e as coisas. A presença e a influência do pensamento nietzschiano em Foucault são bem conhecidas e, de tão grandes, tendem muitas vezes ao mimetismo e à ofuscação. Foucault insistentemente pontou para essa herança e podemos dizer que há entre eles uma profunda proximidade de fundo, uma autêntica comunhão de projetos, que já é visível no período arqueológico e ainda mais explicitamente nos anos 1970, na chamada fase da genealogia do poder.

Mais do que o estruturalismo, entendo que Nietzsche foi a grande inspiração do projeto arqueológico. O interesse pela transgressão, pelas experiências-limite (outras maneiras de pensar), que tanto marcou o pensamento de Foucault (especialmente nos anos 1960), ganha assim todo o seu sentido. É por essa via, de Nietzsche e dos pós-nietzschianos marginais, que Foucault chegou ao tema da morte do homem. Ou seja, Foucault se encontra com os estruturalistas franceses na crítica ao sujeito, mas chegando por outro caminho. Aliás, em entrevistas, Foucault chegou a dizer isso diversas vezes. Em geral, ele tendia a ficar desconfortável com o rótulo de "estruturalista". Em uma entrevista intitulada Michel Foucault explica seu último livro, publicada na revista Magazine Littéraire em 1969, Foucault afirma que o grande valor do estruturalismo não estaria na análise das estruturas, mas sim (e apenas por essa razão) em ter conseguido despertar o pensamento do sono antropológico, revendo o estatuto do sujeito e o privilégio do homem. Foucault afirma que seu método pode até ser inserido no quadro desse processo de transformação, mas "ao lado dele, não nele" (à côté de lui, pas en lui) (FOUCAULT, 2001b, p. 807).

Embora seja inegável que tenha havido certa influência do ambiente estruturalista francês sobre Foucault nos anos 1960, não é exagerado dizer que sua principal referência, no que diz respeito à crítica ao sujeito fundador, foi (e permaneceu sendo) Nietzsche, através, sobretudo, das reflexões de Blanchot e Bataille. Em uma entrevista publicada em 1967 na revista Les Lettres Françaises com o título Sobre as maneiras de escrever a história, Foucault, ao ser questionado quanto ao estatuto único e apaixonado que teria atribuído a Nietzsche em As palavras e as coisas, responde reconhecendo que teve a fraqueza de lhe 
atribuir um estatuto privilegiado e talvez até meta-histórico, e que isso se devia ao fato de a genealogia nietzschiana ter sido muito mais determinante em seu projeto arqueológico do que o estruturalismo (FOUCAULT, 2001a, p. 627). As repetidas referências a Nietzsche, explícitas ou implícitas, sempre demonstram grande admiração e o alçam à condição de principal inspiração. Sendo assim, ao menos se levarmos em consideração a percepção que Foucault tinha sobre seu próprio trabalho, o estruturalismo teria bem menos incidência em sua maneira de pensar que Nietzsche.

Vemos na temática da morte do homem em As palavras e as coisas o eco da denúncia nietzschiana da falsidade presente no "velho e respeitável Eu", que visa colocar por terra a certeza imediata do "eu penso" e apontar para algo além do homem, como se vê nos $\S \S 16-17$ de Além do bem e do mal (NIETZSCHE, 1992, p. 20-22). Nesse sentido, cito Foucault:

Compreende-se o poder de abalo que pôde ter e que conserva ainda para nós o pensamento de Nietzsche, quando anunciou, sob a forma do acontecimento iminente, da Promessa-Ameaça, que, bem logo, o homem não seria mais mas, sim, o super-homem; o que, numa filosofia do Retorno, queria dizer que o homem, já desde muito tempo, havia desaparecido e não cessava de desaparecer, e que nosso pensamento moderno do homem, nossa solicitude para com ele, nosso humanismo dormiam serenamente sobre sua retumbante inexistência. (FOUCAULT, 2007, p. 444).

Em As palavras e as coisas Foucault confere a Nietzsche o papel de ter sido o primeiro a se voltar contra o antropologismo que desde Kant teria marcado o pensamento ocidental. É, portanto, na senda aberta por Nietzsche que Foucault situa claramente seu trabalho, como parte desse trabalho de escavação desenhado por Nietzsche. Cito mais uma vez Foucault:

Talvez se devesse ver o primeiro esforço desse desenraizamento da Antropologia ao qual, sem dúvida, está votado o pensamento contemporâneo, na experiência de Nietzsche: através de uma crítica filológica, através de uma certa forma de biologismo, Nietzsche reencontrou o ponto onde o homem e Deus pertencem um ao outro, onde a morte do segundo é sinônimo do desaparecimento do primeiro, e onde a promessa do super-homem significa, primeiramente e antes de tudo, a iminência da morte do homem. Com isso, Nietzsche, propondo-nos esse futuro, ao mesmo tempo como termo e como tarefa, marca o limiar a partir do qual a filosofia contemporânea pode recomeçar a pensar; ele continuará sem dúvida, por muito tempo, a orientar seu curso. (FOUCAULT, 2007, p. 472-3). 
As palavras e as coisas, ao ter por objeto privilegiado de análise a emergência e a morte do homem, assume esse projeto nietzschiano. Foucault segue claramente a linha de experimentação do pensamento sugerida por Nietzsche, de pensar sem Deus e sem homem. Podemos dizer que Foucault encarna nesse aspecto a figura nietzschiana do "filósofo do futuro" ou do "homem de experimentos", na medida em que realiza um mergulho bem fundo na própria época com o fim de ultrapassá-la. Trata-se um esforço direcionado à realização da tarefa de diagnosticar esse "hoje" no qual vivemos. E se a noção de sujeito fundador deve ser abandonada, isso apenas aponta para um novo desafio intelectual que se apresenta: investigar o processo contingente de fabricação ou constituição dos sujeitos.

O Foucault dos anos 1960 está claramente movido por esse projeto: sua aposta na época de As palavras e as coisas parece ser que o novo modo de pensar poderia estar se desenhando no interior das experiências radicais com a linguagem (como vemos em Roussel, Artaud ou Mallarmé). As pesquisas arqueológicas e as reflexões ensaísticas voltadas para as experiências de linguagem, que marcaram a produção intelectual de Foucault até a época de publicação de As palavras e as coisas (a primeira metade da década de 1960), são dois aspectos indissociáveis de sua tentativa de se libertar da figura do homem. Podemos dizer, seguindo a leitura de Roberto Machado em Foucault, a filosofia e a literatura, que a literatura significou, nesse momento do pensamento foucaultiano, um complemento indispensável às análises arqueológicas, revelando mais claramente o aspecto positivo, afirmativo, de contestação do humanismo moderno (MACHADO, 2005, p. 12). Em suma, a literatura permitiria o aparecimento de uma nova forma de pensar, marcada pela experiência da finitude e da morte do homem. Fica evidenciado aqui o desejo de Foucault de explorar as experiências transgressoras de pensamento, o esforço para se abrir às outras maneiras de pensar. Em suma, Foucault deixa mais uma vez claro o caráter radical e experimental de seu pensamento: um olho voltado para aquilo que somos (e como viemos a nos tornar tal), e outro olho direcionado para o futuro.

\section{A ATITUde CRÍtica: A OUSADIA DE PENSAR NO PROJETO ILUMINISTA E GENEALÓGICO}

Foucault confere à crítica kantiana à metafísica e à sua reflexão sobre os limites da razão uma significação ainda maior, para além da emergência do homem: Kant teria aberto a porta para uma interrogação crítica radical. Em linhas gerais, podemos afirmar que o 
criticismo kantiano é visto por Foucault com grande entusiasmo, como um capítulo transformador e libertador para o pensamento ocidental. Não é sem razão que, em seu último ano de vida, ao ser convidado para escrever o verbete sobre si mesmo no Dictionnaire des philosophes organizado por Denis Huisman (texto esse que foi publicado com a assinatura de um fictício Maurice Florence, nome que permite entrever as inicias do próprio Foucault: M.F.), diz logo na primeira frase Foucault (ou François Ewald, seu assistente que parece ter sido o verdadeiro autor da frase): "Se Foucault se inscreve na tradição filosófica, é então na tradição crítica de Kant que podemos situá-lo, no projeto de uma história crítica de nosso pensamento" (FOUCAULT, 2001b, p. 1450).

Depurado do sono antropológico, o gesto crítico de Kant é claramente defendido por Foucault. Mas, além de eliminar a figura do sujeito transcendental, outro desafio se impõe: introduzir a história no espaço antes ocupado pelo sujeito. É nesse momento que chegamos à polêmica noção de a priori histórico. O conhecimento a priori, como se sabe, é definido por Kant como aquele que é absolutamente independente de toda experiência. Ou seja, os conceitos a priori são vistos como estruturas universais. Certamente não é nesse sentido que Foucault retoma o termo na arqueologia, dado que todo o saber é historicizado. Mas Foucault retém um aspecto, que é a condição de certa experiência do saber. Ainda que histórico e contingente, o saber possui condições de possibilidade que podem ser tomadas como a priori históricos (claro, cometendo aqui uma heresia a Kant).

O sentido kantiano do termo é certamente alterado, mas se preserva algo essencial: o desdobramento de dois níveis de análise, o do discurso e o do que torna possível o discurso. Enfim, para Kant, transcendental é todo conhecimento que se ocupa não dos objetos, mas do nosso modo de conhecer os objetos (e da possibilidade mesma desse conhecimento). Tomado nesses termos bem gerais, a ideia de uma crítica transcendental não parece pressupor a centralidade do sujeito nem a atemporalidade do conhecimento. Trata-se apenas de um deslocamento do ponto de vista: do objeto em favor da relação com o objeto. Na introdução da Crítica da razão pura, Kant deixa esse ponto bem claro:

Chamo transcendental a todo o conhecimento que em geral se ocupa menos dos objetos, que do nosso modo de os conhecer, na medida em que este deve ser possível a priori. Um sistema de conceitos deste gênero deveria denominar-se filosofia transcendental. (KANT, 2001, p. 53, B25). 
Foucault retém aqui uma importante lição de Kant: a centralidade da reflexão sobre as condições de possibilidade do conhecimento e do pensamento. A crítica é, assim, nada mais que uma reflexão sobre os limites. E, nesse sentido, tanto a Crítica da razão pura, quanto As palavras e as coisas, são reflexões sobre os limites do conhecimento e do pensamento. Rodrigo Orellana tem toda razão ao dizer que "se pode sustentar, com toda legitimidade, que a obra de Foucault se caracteriza por um retorno permanente à reflexão kantiana, por meio de uma compreensão da filosofia como experiência dos limites" (ORELLANA, 2006, p. 171, tradução minha). A diferença está na forma como essa reflexão é conduzida (no papel conferido ao homem e à história). Deslocado dessa forma por Foucault, como veremos a seguir, o gesto crítico introduzido por Kant aponta para uma questão que tenderá a tornar-se central na filosofia: a atualidade. Ou seja, a problematização de nossa maneira de ser, de pensar e de agir. Em suma, uma ontologia do presente.

Em outras palavras, a arqueologia faz um grande esforço de historicização da crítica kantiana, de modo que a função que Kant atribuía ao sujeito, a arqueologia atribuirá a uma configuração histórica específica. Dessa maneira, a crítica transcendental perderá também o seu alcance universal (valendo para todo conhecimento humano possível) e passará a ser uma crítica historicamente delimitada, que vale para certa conformação de saber contingente. Assim, a crítica que antes identificava as limitações necessárias da razão humana, agora, com Foucault, assume a forma de uma possível transgressão, de outra maneira de pensar que pode emergir. Já que os limites deixam de ser universais e necessários, eles estão sempre abertos a mudanças.

Em seu último ano de vida, Foucault publicou uma instigante leitura da resposta kantiana à questão Was ist Auflärung?, na qual vemos se delinear mais claramente como a crítica kantiana é por ele apropriada e reivindicada. ${ }^{2}$ Kant, tão atacado anteriormente em razão da centralidade conferida ao sujeito transcendental e por ter embalado o pensamento ocidental no sono antropológico, fazendo a crítica recair em um novo dogmatismo, é então identificado

\footnotetext{
${ }^{2}$ Uma primeira versão dessa leitura de Foucault aparece em 1978, em uma apresentação realizada na Sorbonne para a Sociedade Francesa de Filosofia intitulada "O que é a crítica?: Crítica e Aufklärung" (Qu'est-ce que la Critique?: Critique et Aufklärung), texto não publicado nos Ditos e escritos (FOUCAULT, 1990). Depois, essa leitura reaparece na aula de 5 de janeiro de 1983 no Collège de France, a primeira do curso intitulado O governo de si e dos outros (FOUCAULT, 2010, pp. 3-24). E em 1984, ano de comemoração do bicentenário do texto de Kant publicado na Berlinische Monatsschrift em resposta à questão Was ist Auflärung? (KANT, 1985), vemos duas versões dessa interpretação de Foucault serem publicadas: uma versão francesa (Qu'est-ce que les Lumières?) e uma versão inglesa ampliada (What is Enlighthenment?), ambas incluídas nos Ditos e escritos (FOUCAULT, 2001e; FOUCAULT, 2001c).
}

Sapere aude - Belo Horizonte, v. 7 - n. 12, p. 7-21, Jan./Jun. 2016 - ISSN: 2177-6342 
a uma nova atitude filosófica, com a qual Foucault se identifica. Como ressalta Howard Caygill em seu Dicionário Kant, no verbete dedicado ao iluminismo, Foucault e outros filósofos contemporâneos que seguem a via aberta por Nietzsche não devem ser vistos como adversários da Aufklärung, mas "parece mais exato descrevê-los como autores quintessencialmente esclarecidos, exploradores públicos, dentro de um espírito distintamente kantiano, das consequências da ampliação do impulso crítico do Iluminismo à própria razão" (CAYGILL, 2000, p. 184).

A principal característica desta "atitude de modernidade", na leitura feita por Foucault, residiria no desenvolvimento de uma reflexão ao mesmo tempo histórica e crítica. Isso porque se trataria de uma crítica de nosso presente e de nós mesmos. O próprio Kant é lido dessa forma, como aquele que, pela primeira vez, colocou a questão do presente na filosofia. Essa leitura, que Foucault realiza ao final de sua vida, tem o poder de religar o primeiro ao último Foucault, estabelecendo uma passagem e uma espécie de continuidade entre suas reflexões dos anos 1960 sobre as formações discursivas e suas últimas reflexões sobre a vida filosófica (FIMIANI, 1998, p. 15). De certa maneira, Foucault parece descrever seu projeto filosófico como uma espécie de reescrita do kantismo, no seio do qual a crítica de origem iluminista se conecta a uma reflexão histórica sobre as condições de verdade e liberdade.

Nessa nova leitura de Kant, Foucault deixa claro que, mais do que uma afirmação da centralidade do homem, o que caracterizaria o iluminismo seria a atitude crítica de modernidade, a ousadia de pensar sobre quem somos nós na atualidade. A pergunta central para os modernos não seria então “o que é o homem?", mas sim a análise dos limites que faz com que sejamos o que somos hoje. Em suma, o antropologismo moderno, que é o tema discutido em As palavras e as coisas, permanece alvo das mais severas críticas, mas deixa de ser identificado como o centro do pensamento kantiano. O que sobrevive de Kant e dos modernos, aos olhos de Foucault, é a atitude crítica voltada para o presente.

Convém lembrar aqui a definição que Kant oferece da Aufklärung logo no primeiro parágrafo de seu texto sobre essa questão, naquela que é talvez uma das linhas mais famosas da história da filosofia: "Esclarecimento (Aufklärung) é a saída do homem de sua menoridade, da qual ele próprio é culpado. A menoridade é a incapacidade de fazer uso de seu entendimento sem a direção de outro indivíduo" (KANT, 1985, p. 100, A 481). Ao atingir o estado de maioridade, o homem ousa não mais se deixar conduzir, não mais ser governado pelos outros em seu pensamento e em sua conduta. Assim, a crítica associa-se claramente a uma atitude moral e política, que Foucault irá relacionar à arte de não ser governado, ou seja, 
ao exercício de uma liberdade que conhece seus próprios limites e que está em condições de transformar sua relação com o poder. Assim como Kant, também Foucault, ao seu modo próprio, leva adiante o sonho iluminista da luta pela liberdade.

$\mathrm{Na}$ leitura de Foucault, esse ethos filosófico inaugurado por Kant caracteriza-se por ser uma atitude limite que realiza uma crítica permanente de nosso ser histórico, não uma negação ou rejeição, mas sim uma análise sobre os limites, que aponta para a possibilidade de deixarmos de ser o que somos e de nos transformarmos em algo radicalmente outro. Em suma, esse novo ethos filosófico que Foucault associa à atitude de modernidade inaugurada por Kant, realiza também uma análise dos limites, como fez a crítica transcendental, com a diferença que, ao invés de ser meramente negativa, ela assume uma postura positiva, de transformação. Segundo Foucault: "É preciso concebê-la [a ontologia crítica de nós mesmos] como uma atitude, um ethos, uma vida filosófica na qual a crítica daquilo que somos é, ao mesmo tempo, análise histórica dos limites que nos são postos e experimentação de sua ultrapassagem possível” (FOUCAULT, 2001a, p.1396, tradução minha).

Inspirado nesta "atitude de modernidade", Foucault delineia a noção de uma nova postura crítica, ao mesmo tempo localizada e experimental, que se restringe a análises históricas dentro de domínios específicos e que aponta sempre para a possibilidade de transgressão. Sendo assim, a crítica genealógica é claramente aproximada da crítica iluminista. A atualidade, ou seja, a questão sobre quem somos nós hoje, é o ponto de partida de todo trabalho crítico. Trata-se de retraçar um processo, de identificar a emergência das formas de ser, de pensar e de agir que são ainda, em grande medida, as nossas.

Nesse ponto, mais uma vez é claramente sentida a presença de Nietzsche. Foucault aproxima a atitude de modernidade e a crítica kantiana à genealogia e à ontologia do presente. Se a crítica kantiana ressalta os limites de nosso pensamento, a crítica genealógica se serve da história para retirar a suposta evidência e naturalidade de nossas maneiras de ser e de pensar. Passamos a perceber que aquilo que somos é resultado de um processo contingente e que podemos ser absolutamente diferentes, radicalmente "outros" em relação àquilo que nos tornamos. Não há nada de universal, de natural, de necessário, de originário ou de puro naquilo que somos. A crítica genealógica aponta para a importância de se investigar a história da verdade (para além do verdadeiro e do falso), a história da moral (para além do bem e do mal) e a história do sujeito (para além do homem). Na perspectiva nietzschiana, nem Deus, nem o homem, nem a verdade e nem o bem são descobertos: eles são inventados. E, assim 
com são produzidos e fabricados em determinada época, podem também ser mortos, destruídos e superados em outras.

\section{CONCLUSÃO}

Foucault inicia As palavras e as coisas afirmando que o livro teria nascido de um texto de Jorge Luis Borges. O texto em questão é o conto intitulado O idioma analítico de John Wilkins, no qual aparece uma citação de uma velha enciclopédia chinesa supostamente intitulada Empório Celestial do Conhecimento Benevolente na qual os animais são divididos em 14 categorias: “a) pertencentes ao imperador, b) embalsamados, c) domesticados, d) leitões, e) sereias, f) fabulosos, g) cães em liberdade, h) incluídos na presente classificação, i) que se agitam como loucos, $\mathrm{j}$ ) inumeráveis, $\mathrm{k}$ ) desenhados com um pincel muito fino de pêlo de camelo, 1) et cetera, m) que acabam de quebrar a bilha, n) que de longe parecem mosca" (BORGES, apud FOUCAULT, 2007, p. ix). Foucault afirma que esse texto de Borges o teria feito rir durante muito tempo, "mas não sem um mal-estar evidente e difícil de ser superado" (FOUCAULT, 2007, p. xii). E esse mal-estar reside, em grande medida, em nossa impossibilidade de pensar isso, o que parece desnudar a limitação de nosso próprio pensamento. Como se pergunta Foucault: “que coisa, pois, é impossível pensar, e de que impossibilidade se trata?" (FOUCAULT, 2007, p. ix).

Não é sem razão que essa é a primeira pergunta que lemos em As palavras e as coisas, logo na primeira página do prefácio. É essa pergunta desconcertante que parece realmente mover toda a reflexão do livro. Uma pergunta que aponta para uma clara reflexão crítica, acerca dos limites de nosso pensar. O conto de Borges, ao nos provocar riso e mal-estar, aponta para outra "ordem das coisas", para outras maneiras de pensar, para esses outros lugares e esses "homens outros".

Vendo por esse ângulo, As palavras e as coisas parece nos deixar um claro ensinamento. Para além dos conceitos introduzidos e das escolhas metodológicas empregadas, creio que Foucault oferece outro legado importantíssimo, uma espécie de atitude ou ethos filosófico. Mais do que algo a ser empregado (usado em nossas pesquisas), trata-se algo a ser incorporado em nossa ação, uma espécie de exemplo a ser seguido, algo a ser posto em prática em nossas próprias experiências de pensamento. Nesse sentido, As palavras e as coisas ganha seu valor não exatamente pela obra grandiosa que é ou pelas ferramentas que 
oferece (que são muitas, indiscutivelmente). Acima de tudo, trata-se de uma experiência de pensamento transformadora.

Nesses termos, As palavras e as coisas deve ser vista como um ponto em uma curva que desenha um trajeto, um eterno vir a ser, um processo incessante de transformação, no qual sempre deixamos de ser aquilo que somos para assumir novas formas. Foucault aponta neste livro para essas outras maneiras de pensar, livres do sono antropológico, e é essa atitude questionadora, crítica, transformadora, que deve mover a filosofia. Cinquenta anos depois, esse exemplo permanece vivo. Mais do que repetir ou comentar incessantemente o já-dito, o que se impõe é incorporar a mesma atitude e seguir adiante. Assim, é preciso voltar a As palavras e as coisas não para ficar preso nesta obra monumental, mas sim para ver nela um vetor, uma seta que aponta para além. Com Kant, com Nietzsche, com Foucault, e além.

\section{REFERÊNCIAS}

CALVINO, Ítalo. Por que ler os clássicos. Tradução Nilson Moulin. São Paulo: Companhia das Letras, 1993.

CANDIOTTO, César. Michel Foucault e o problema da antropologia. Revista Philosophica, v. 29, Valparaíso, p. 183-197, semestre I, 2006.

CAYGILL, Howard. Dicionário Kant. Tradução Álvaro Cabral. Rio de Janeiro: Jorge Zahar, 2000.

DEKENS, Olivier. Michel Foucault: "A verdade de meus livros este no futuro". Tradução Roberto Mesquita Ribeiro. São Paulo: Loyola, 2015.

FIMIANI, Mariapaola. Foucault et Kant: critique, clinique, éthique. Trad. Nadine Le Lirzin. Paris: L’Harmattan, 1998.

FOUCAULT, Michel. Les mots et les choses: une archéologie des sciences humaines. Paris: Gallimard, 1966.

FOUCAULT, Michel. Qu'est-ce que la critique ? Critique et Aufklärung. Bulletin de la Société française de philosophie, v. 82, n. 2, p. 35-63, avr/juin 1990.

FOUCAULT, Michel. Michel Foucault explique son dernier livre (1969). In: FOUCAULT, Michel. Dits et Écrits, v. 1: 1954-1975. Paris: Gallimard, collection «Quarto», p. 799-807, $2001 b$.

FOUCAULT, Michel. What is Enlightenment? («Qu'est-ce que les Lumières ? ») (1984). In: FOUCAULT, Michel. Dits et Écrits, v. 2: 1976-1988. Paris: Gallimard, collection «Quarto», p. 1381-1397, 2001c. 
FOUCAULT, Michel. Foucault (1984). In: FOUCAULT, Michel. Dits et Écrits, v. 2: 19761988. Paris: Gallimard, collection «Quarto », p. 1450-1455, 2001d.

FOUCAULT, Michel. Qu'est-ce que les Lumières ? (1984). In: FOUCAULT, Michel. Dits et Écrits, v. 2: 1976-1988. Paris: Gallimard, collection «Quarto», p. 1498-1507, 2001e.

FOUCAULT, Michel. As palavras e as coisas: uma arqueologia das ciências humanas. $9^{\mathrm{a}}$ ed. Tradução Salma Tannus Muchail. São Paulo: Martins Fontes, 2007.

FOUCAULT, Michel. O governo de si e dos outros: curso no Collège de France (19821983). Tradução Eduardo Brandão. São Paulo: WMF Martins Fontes, 2010.

HUTCHINGS, Kimberly. Kant, critique and politics. London/New York: Routledge, 1996.

KANT, Immanuel. Resposta à pergunta: O que é Esclarecimento? / Beantwortung der Frage: Was ist Aufklärung? (edição bilíngue). In: KANT, Immanuel. Textos selecionados. $2^{\mathrm{a}}$ ed. Tradução Floriano de Sousa Fernandes. Petrópolis: Vozes, p. 100-117, 1985.

KANT, Immanuel. Crítica da razão pura. $5^{\mathrm{a}}$ ed. Tradução Manuela Pinto dos Santos e Alexandre Fradique Morujão. Lisboa: Fundação Calouste Gulbenkian, 2001.

ORELLANA, Rodrigo Castro. Foucault y el retorno de Kant. Teorema, v. XXIII, n. 1-3, p. 171-179, 2004.

MACHADO, Roberto. Foucault, a filosofia e a literatura. $3^{\text {a }}$ ed. Rio de Janeiro: Jorge Zahar Editor, 2005.

NIETZSCHE, Friedrich. Além do bem e do mal: prelúdio a uma filosofia do futuro. Tradução Paulo César de Souza. São Paulo: Companhia das Letras, 2005. 